\title{
Acute focal bacterial nephritis is associated with invasive diagnostic procedures - a cohort of 138 cases extracted through a systematic review
}

\author{
Nadine Sieger ${ }^{1 *}$ D, lason Kyriazis ${ }^{1,2}$, Alexander Schaudinn ${ }^{3}$, Panagiotis Kallidonis ${ }^{2}$, Jochen Neuhaus ${ }^{1}$,
} Evangelos N. Liatsikos' ${ }^{2}$ Roman Ganzer ${ }^{1}$ and Jens-Uwe Stolzenburg ${ }^{1}$

\begin{abstract}
Background: Acute focal bacterial nephritis (AFBN) is a rare disease currently described only in case reports and small case series. In this study we summarize the clinical features of AFBN as has been documented in the literature and draw recommendations on the proper diagnosis and therapy.

Methods: A systematic literature review was undertaken in PUBMED, Web of Science and The Cochrane Library online databases for relevant literature on AFBN in adults.

Results: Literature review revealed a total of 38 articles according to our inclusion criteria, of which we could extract data from 138 cases of AFBN. Fever (98\%) and flank pain (80\%) were most commonly reported symptoms. E. coli was the most frequent pathogen. Diagnosis was set by $C T$ and/or MRI (52\%) with or without sonography or by sonography alone (20\%) as well as by sonography combined with IVU. In total, sonography was applied in $83 \%$ of cases. All but one patient received antibiotic treatment. Kidney lesions were occasionally mistaken for neoplasms or renal abscesses and as a result, cases were subjected to percutaneous puncture (12.3\%), surgical exploration (5.1\%) and partial or radical nephrectomy (4.4\%). Four cases (2.9\%) developed a renal abscess.

Conclusions: The diagnosis of AFBN is set by characteristic clinico-radiological findings. Differential diagnoses of this interstitial bacterial infection include renal abscess and tumor. Correct diagnosis is occasionally impeded by atypical symptoms. Invasive diagnostic and therapeutic procedures should be limited as the majority of cases respond well to conservative treatment.
\end{abstract}

Keywords: Focal nephritis, Renal infection, Upper urinary tract infection, Pyelonephritis

\section{Background}

Acute focal bacterial nephritis was first described in 1978 by Rosenfield et al. [1]. It was then named "acute lobar nephronia", in analogy to acute lobar pneumonia, as the anatomic extent of the infection is sometimes determined by the renal lobes. AFBN is a rare focal bacterial interstitial infection of the kidney presenting with characteristic focal lesions in radiological imaging (Fig. 1). Focal lesions seen in AFBN are occasionally misdiagnosed and patients are at

\footnotetext{
* Correspondence: nadine.sieger@hotmail.com

${ }^{1}$ Department of Urology, University Hospital Leipzig, Liebigstraße 20, 04103

Leipzig, Germany

Full list of author information is available at the end of the article
}

risk to receive unnecessary invasive procedures [1-4]. Given that AFBN is poorly described in the literature as available information predominantly consists of case reports and small case series, in this work, we conducted a systematic review of the literature in an attempt to summarize clinical presentation of the disease and make recommendations on its management.

\section{Methods}

A systematic review of the literature on AFBN was conducted on PUBMED, Web of Science and The Cochrane Library online databases on July 2014. Search terms used were (focal[Title/Abstract]) AND *nephritis[Title/Abstract] 

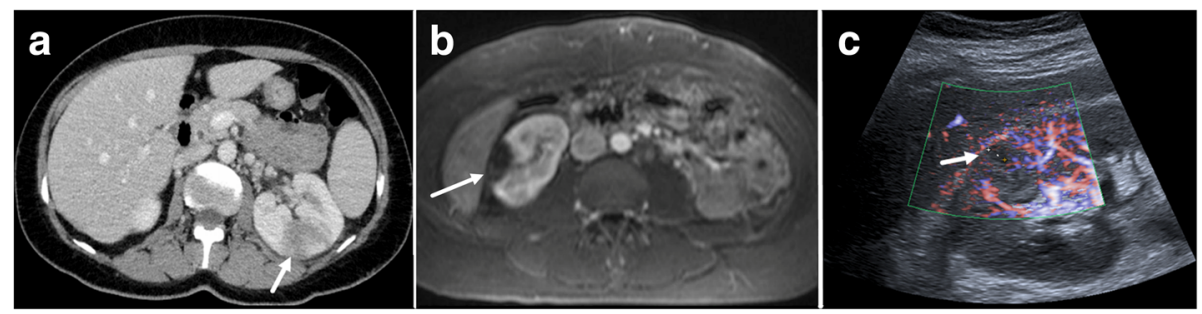

Fig. 1 Imaging findings for AFBN. a-c Typical image findings for AFBN in CT (a), MRI (b) and Ultrasound (c). Post-contrast axial CT and MRI (T1W VIBE) showing areas of poor enhancement in the right kidney (arrows) in wedge (a) and round shape (b). Colour Doppler enhanced Ultrasound image (c) with arrow indicating focal hypoperfusion

in PUBMED and focal AND *nephritis (Title) in Web of Science and focal AND *nephritis (Title, Abstract, Keywords) in The Cochrane Library. We applied the Preferred Reporting Items for Systematic Reviews and Meta-analysis (PRISMA) flow diagram [5]. After eliminating duplicates, we screened publications by their title. Two independent authors (NS and IK) assessed abstracts and full texts of selected publications for the following eligibility criteria: Articles on AFBN published in english, spanish, italian, french and german; we excluded publications not written in Roman letters. Articles on AFBN in human adults; we excluded articles on pediatric cases apart from four case series reporting mixed children's and adult's cases. Articles providing at least information about clinical presentation, radiologic findings, therapeutic procedures and course of the disease; radiologic characteristics were to indicate AFBN. Disagreements were resolved by discussion and consensus.

A standardized form was used to extract the following data from articles: study design; patient age; gender; symptoms; presence of leukocytosis; urinalysis; pathogen identified by urine and/or blood culture and/or biopsy; previous illness; genitourinary tract abnormalities; type of diagnostic imaging and findings; therapy; choice of antibiotic; invasive procedures; course of disease; follow up.

An update of search was performed in November 2015 revealing no additional studies that fulfilled our inclusion criteria.

\section{Results}

\section{Article selection}

We included 38 publications according to our selection criteria. Out of these, we were able to extract clinical data from a total number of 138 cases (Table 1). The flow chart of our search strategy and article selection is presented in Fig. 2.

\section{Clinical findings in AFBN}

\section{Fever and flank pain are leading symptoms}

AFBN is commonly presented with fever (reported in $98 \%$ of the cases) and leukocytosis, indicating severe illness and sepsis. Similar to acute pyelonephritis, ipsilateral flank pain is commonly encountered (80\%), while dysuria and/ or symptoms of lower urinary tract infection (UTI) were reported only in $18 \%$ of the cases in our cohort. Nonspecific symptoms such as nausea, vomiting and abdominal pain or guarding may be present complicating differential diagnosis (Fig. 3). Palpation of an abdominal mass was reported in $7 \%$ of cases $(n=10)[3,6,7]$.

\section{E. coli is the predominant pathogen}

The most frequent pathogen isolated in urinary cultures of patients with AFBN is Escherichia coli. In our cohort it was detected in $83 \%$ of all positive urine cultures. Sporadically, other gram negative bacteria such as Klebsiella species [1, 8, 9], Proteus mirabilis [10] and Serratia marcescens [11] have been isolated. Urine cultures were negative in $41 \%$ of cases. A summary of urine microbiologic findings is depicted in Fig. 4. Blood cultures were positive in $19 \%$ of cases and were negative or not specified for the rest. E. coli was also most commonly isolated in blood cultures representing 69\% of positive blood cultures (Fig. 5). It is of worth mentioning that in $2.2 \%$ of the cases $(n=3)$ there was a strong indication of hematogenous spread. Staphylococcus aureus bacteremia was present in all these cases with concurrent AFBN and skin abscess [12], osteomyelitis [8] or glenohumeral septic arthritis [13]. One of the latter cases developed a renal abscess [12].

\section{No underlying illness in the majority of cases}

AFBN occurs more often in women than in men (ratio 2:1 in our cohort) and affects all ages from childhood to the elderly patient. Immune compromising diseases as well as other predisposing factors are associated with the formation of AFBN according to our cohort, such as Diabetes mellitus $[1,8,9,13-18]$, pregnancy $[4,14,19]$, urinary tract abnormalities $[1,3,4,8-10,14,20,21]$, prior or concurrent respiratory tract infection $[3,4,16]$, former kidney transplantation [7, 22-24], alcohol and drug abuse [2, 25, 26], autoimmune diseases $[1,6,10]$ and AIDS [25] (Table 2). Yet it has to be emphasized that AFBN also affects previously healthy immunocompetent patients. 
Table 1 Selected publications

\begin{tabular}{|c|c|c|}
\hline Year & Author (et al.) & Number of cases (age, sex) \\
\hline 1979 & Rosenfield & $13(1-66, f=6, m=6$, not specified $=1)$ \\
\hline 1980 & Lee & $13(24-82, f=8, m=5)$ \\
\hline 1981 & McDonough & $4(26-49, f)$ \\
\hline 1982 & Funston & $3(44-52, f)$ \\
\hline 1983 & Angulo & $1(31, m)$ \\
\hline 1984 & Dochy & $1(35, \mathrm{f})$ \\
\hline 1985 & Mc Coy & $1(43, f)$ \\
\hline 1985 & Zaontz & $9(20-86, f=8, m=1)$ \\
\hline 1986 & Rigsby & $5(17-40, f=4, m=1)$ \\
\hline 1986 & Schmidt & $5(16-35, f=3, m=2)$ \\
\hline 1988 & Cox & $1(19, f)$ \\
\hline 1988 & Derouet & $1(22, \mathrm{~m})$ \\
\hline 1988 & Harpole & $1(57, f)$ \\
\hline 1988 & Nosher & $12(5-62, f=9, m=3)$ \\
\hline 1990 & Cuenca & $1(67, f)$ \\
\hline 1991 & Dourthe & $1(26, \mathrm{~m})$ \\
\hline 1992 & Harris & $1(34, f)$ \\
\hline 1992 & Levy & $1(33, f)$ \\
\hline 1992 & Sawamura & $2(35-40, m)$ \\
\hline 1993 & Thomalla & $1(22, \mathrm{~m})$ \\
\hline 1994 & Cho & $24(7-78, f=20, m=4)$ \\
\hline 1994 & Ruiz Dominguez & $1(40, f)$ \\
\hline 1994 & Yang & $1(42, m)$ \\
\hline 1995 & Boam & $1(75, \mathrm{~m})$ \\
\hline 1995 & Wood & $1(73, \mathrm{~m})$ \\
\hline 1996 & $\mathrm{Li}$ & $15(16-56, f=5, m=10)$ \\
\hline 1996 & Pelage & $2(24-31, f)$ \\
\hline 1996 & Rosi & $3(11-43, f)$ \\
\hline 2000 & Kumar & $1(44, \mathrm{~m})$ \\
\hline 2001 & Esteban & $1(43, f)$ \\
\hline 2001 & Falcon & $1(37, \mathrm{~m})$ \\
\hline 2002 & Ameur & $1(24, \mathrm{~m})$ \\
\hline 2002 & Montejo & $4(20-65, f)$ \\
\hline 2004 & Joss & $1(28, f)$ \\
\hline 2011 & Čustović & $1(52, f)$ \\
\hline 2013 & Adams & $1(33, f)$ \\
\hline 2014 & lga & $1(50, m)$ \\
\hline 2014 & Maeshiro & $1(23, f)$ \\
\hline
\end{tabular}

\section{Diagnostic imaging}

\section{CT and sonography are preferred for diagnosis of AFBN}

The diagnosis of AFBN is dependent on radiologic imaging. AFBN is characterized by hypoperfused wedged-shaped or round and space-occupying lesions in the kidney, exhibiting no capsule. Lesions can be uni- or multifocal. In our cohort
$52 \%$ of patients received computed tomography (CT) and/or magnetic resonance imaging (MRI) during acute phase of AFBN all of them showing characteristic focal lesions. MRI was applied only in $2.9 \%$ of cases. Sonography in addition to CT and/or MRI was performed in $41 \%$ and had $91 \%$ sensitivity in this subgroup. In total, sonography was applied in $83 \%$ of cases (solely or combined with intravenous urography (IVU) and/or CT and/or MRI). Relating to the total amount of sonographies this diagnostic modality had $96 \%$ sensitivity in our cohort. $20 \%$ of the diagnoses were solely set by sonography. Radiologic features are summarized in Table 3.

In native CT lesions are hypodense, showing decreased enhancement after intravenous application of contrast agent in comparison to normal parenchyma [3, $4,8,9,27,28]$. They do not show cortical rim sign and thus wedged-shaped lesions can be differentiated from renal infarction [29]. Associated perinephric fat stranding might be present $[12,30]$. The absence of contrast enhancement at lesion margins and the non-liquefactive density may enable the differentiation to renal abscess formation.

MRI was not often employed for AFBN according to the literature. In MRI focal lesions are hypointense in T2w, showing decreased enhancement in post-contrast T1w images [19, 31-33]. Relying data on diffusion weighted imaging is lacking, but lesions commonly show a certain degree of diffusion restriction in correlation to histopathological findings with high levels of cell-density in affected parenchyma.

In sonography focal lesions can be either hypo- or hyperechoic [10, 34, 35]. Doppler ultrasound with or without contrast enhancement confirms decreased focal blood flow [36]. In several cases there were no sonographic abnormalities while AFBN lesions were evident in CT [6, 18, 30, 34, 37, 38].

Arteriographic data on AFBN are available from publications from 1979 to 1992 confirming focal hypoperfusion. Application of this invasive technique was not mentioned beyond 1992. Similarly, employment of IVU for AFBN was last reported in 2002 [39]. IVU might suggest a renal mass with no or delayed contrast excretion or rather lack abnormalities [27, 33, 40].

\section{Histopathology}

Histopathological data on AFBN were obtained by renal biopsies and (partial) nephrectomies. Focal lesions correspond to a zone of disturbed blood flow due to interstitial edema and perivascular inflammatory cells as well as mononuclear cells obstructing the veins. The formation of micro-abscesses might be present but there is no drainable pus $[1,2,7,17,23]$. 


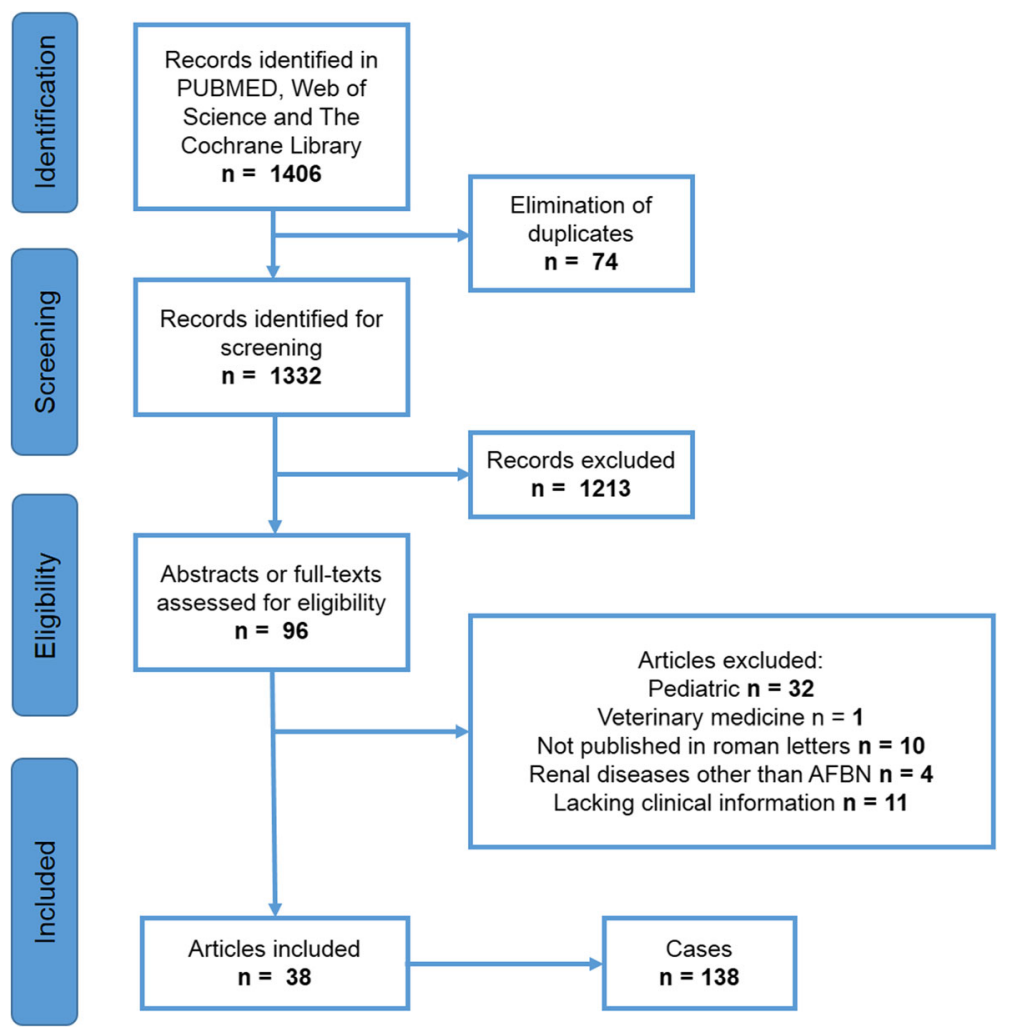

Fig. 2 PRISMA Flow chart - Selection of publications

\section{Treatment and interventions}

\section{Antibiotic therapy is the treatment of choice}

All but one patient in our cohort received antibiotic treatment. The latter case was suspected for having a renal tumor and was directly treated with nephrectomy [3]. There is no standard regimen for choice of antibiotic agent and duration of antimicrobial therapy. The choice of antimicrobial agents was not specified in $82 \%$ of the cases. If specified, cephalosporins were most commonly used followed by broad-spectrum penicillins. Duration of treatment and hospitalization was very variable and not precised in most of the case reports. Duration of antibiotic treatment ranged up to 6 weeks. An uneventful course was reported after conservative management with antibiotics in the vast majority of cases. Still, treatment failure requiring additional measures was also reported. Four patients (2.9\%) developed a renal abscess, three of which required drainage [11, 12, 26, 28]. One of the latter exhibited methicillin-resistant Staphylococcus aureus (MRSA) bacteremia. Two patients (1.5\%) underwent percutaneous puncture due to persisting fever. Aspirates showed no drainable pus but grew Pseudomonas aeruginosa [23] and MRSA [30] respectively and adaptation of antibiotic therapy led to a favorable disease course for both patients. Two patients (1.5\%) required ureteral stenting or stone extraction due to underlying obstructive lithiasis $[4,16]$ and three patients $(2.2 \%)$ underwent nephrectomy because of reported non-response to antibiotic therapy or rather therapeutic mismanagement [1]. In addition to the above-named interventions further invasive procedures were applied in a significant number of cases due to uncertainty in diagnosis of AFBN, most commonly suspicion for a renal malignancy or abscess. A summary of all invasive procedures is shown in Table 4.

\section{Relapses were rarely reported}

Clinical relapse after initial treatment was reported in $2.9 \%$ of cases $(n=4)$. Three out of the four patients recovered upon conservative re-treatment $[1,8]$. One patient exhibiting poor general state of health and noncompliance with the ongoing oral medication after discharge returned septic and died [28].

\section{Follow-up}

Follow-up was not systematically performed according to the literature. Range of follow-up varied greatly from a short period to up to 4 years after disease onset and was performed by sonography, IVU, CT or MRI. There is evidence that radiologic residues of AFBN are frequently detected between ten days to 4 weeks after disease onset despite of reduction of symptoms. Four to eight weeks after disease onset the majority of reported 


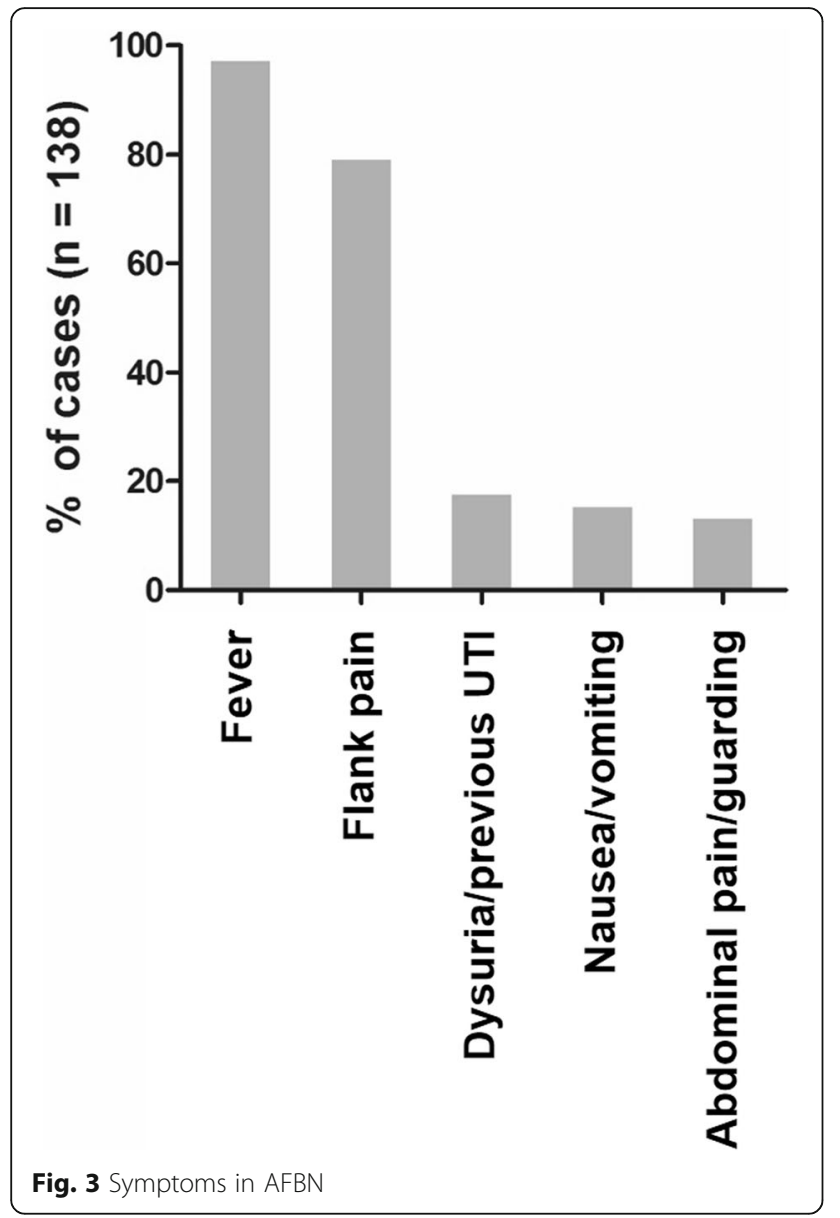

radiologic investigations revealed no residues. Still, late renal scaring has been documented in $4.4 \%$ of cases $(n=6)$. CT [38], sonography $[1,10,23]$ and IVU [28] in those cases showed focal parenchymal wasting or increased echo but patients were asymptomatic and no clinical relevance was reported to be related to these findings.

\section{Discussion}

While AFBN was first described in 1978, it wasn't until the establishment of CT and MRI as standard radiologic investigations in the following years, when a more detailed imaging of the kidney made AFBN a distinct clinical entity. Nevertheless, its diagnosis and management remain a challenge for clinicians and radiologists, as evidenced by the frequent application of redundant invasive interventions, due to its infrequent incidence. The aim of our study is to summarize accumulated knowledge by grouping the numerous case reports into a single large cohort of patients. Obviously, such analysis entails limitations that should be taken into consideration during interpretation of our results. As our dataset is dependent on individual authors' reports, a selection and reporting bias is present; AFBN cases undergoing an uneventful course are less likely to be reported than cases with adverse outcomes; overtherapy

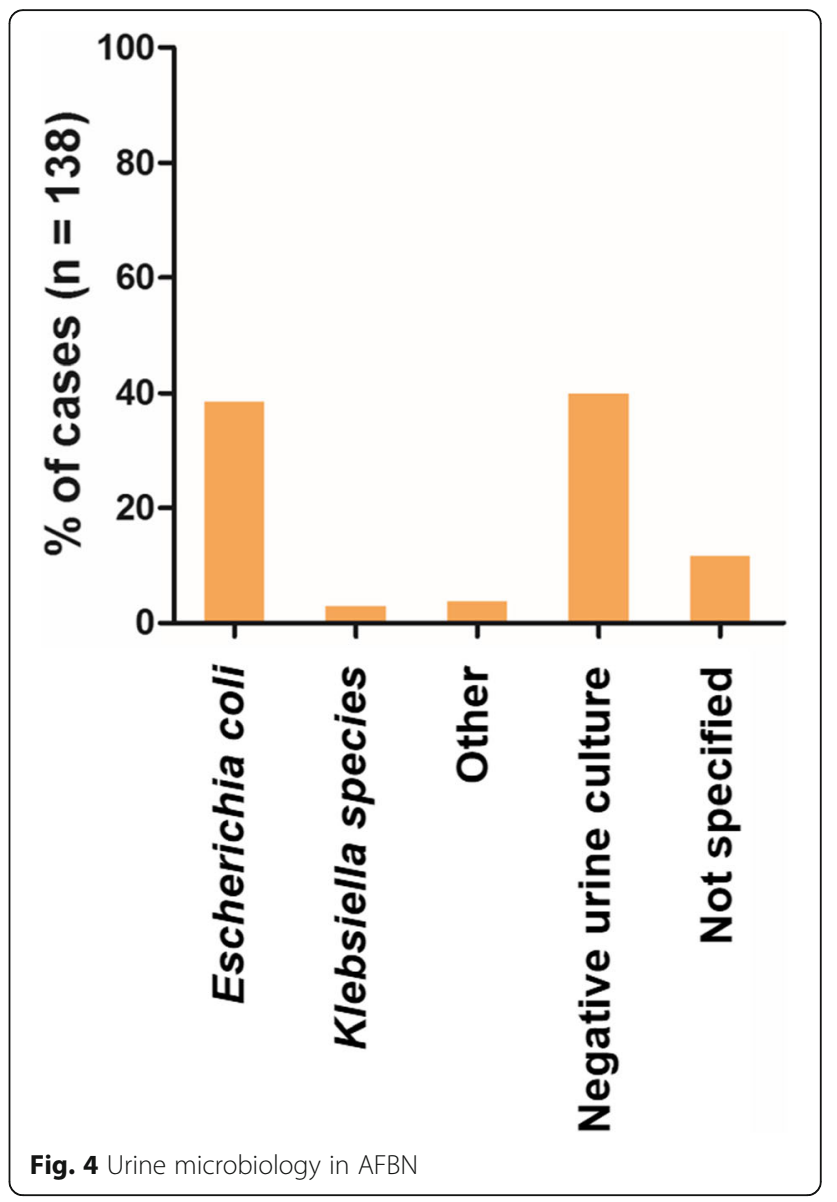

(e. g. nephrectomy) in a case of AFBN is not commendable and therefore less likely to be reported.

AFBN may be underdiagnosed. Based on the presence of clinical symptoms of upper UTI only (fever and flank pain with or without dysuria) AFBN cannot be distinguished from acute pyelonephritis (AP). Sonography has shown high sensitivity (91-96\%) in our cohort but there is evidence that CT and MRI are superior in diagnosing AFBN [18, 34, 37]. High sensitivity of ultrasound might be due to a selection bias (AFBN cases showing evident characteristic pathologies in ultrasound are more likely to be reported). As a result, if CT scan was performed in every patient exhibiting signs for upper UTI, AFBN would probably be diagnosed more frequently. AP can also present with radiological signs (renal enlargement, (diffuse) disturbance of perfusion in renal parenchyma) but in contrast to AFBN radiologic evidence is not mandatory for diagnosis of AP. As soon as localized uni- or multifocal lesions are detected the term acute focal (or multifocal) bacterial nephritis should be used implicating a higher risk for complicated disease course and redundant interventions. It is not relevant to distinguish all cases of AFBN from AP but to identify serious and atypical courses of AFBN requiring special attention and prolonged treatment. 


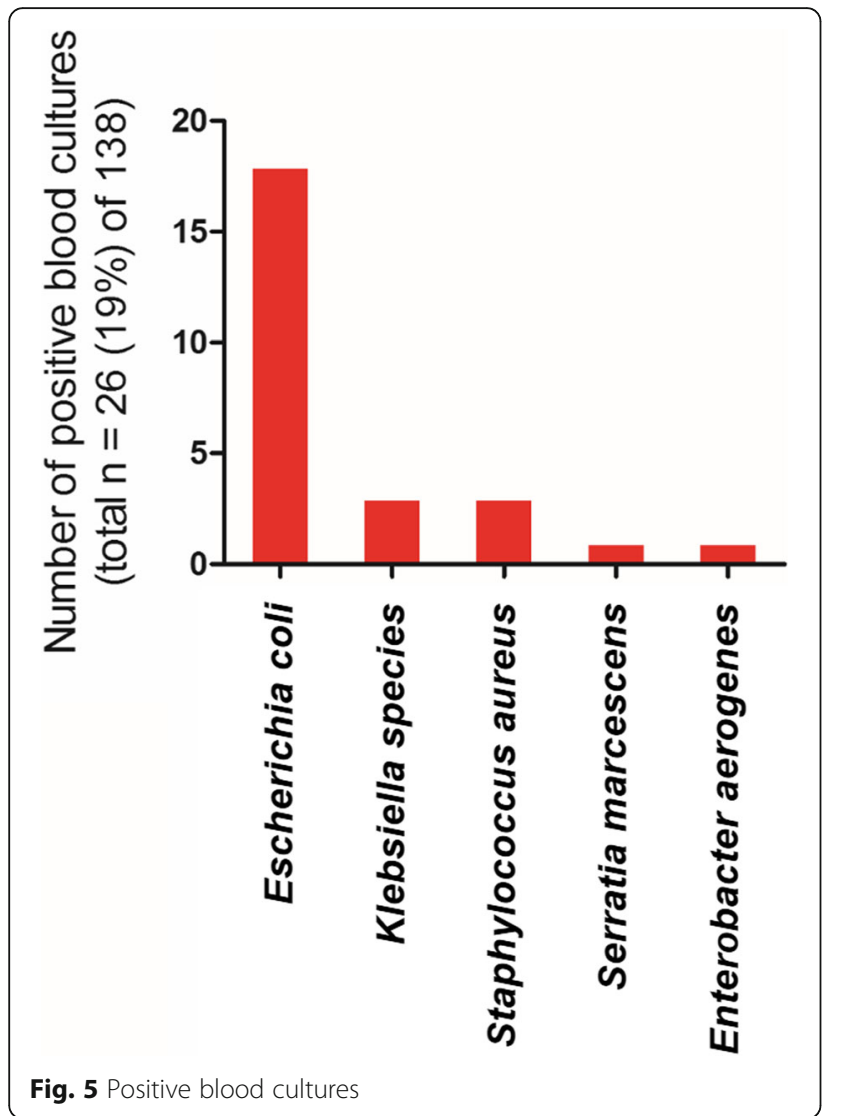

The pathophysiological mechanism of AFBN remains unclear. Hematogenic spread might play a particular role in this disease as the localization of focal lesions seem to correspond to the blood supply pattern of renal segmental arteries, suggesting that focal renal infections are caused by dissemination of bacterial emboli [3]. Presence of a known source of distant infection (skin abscess, osteomyelitis,

Table 2 Predisposing illness and factors in patients with AFBN

\begin{tabular}{ll}
\hline & $\%(\mathrm{n})$ \\
\hline Diabetes mellitus & $12.3(17)$ \\
Pregnancy & $5.8(8)$ \\
Renal stones without obstructive uropathy & $5.1(7)$ \\
Vesicoureteral reflux & $3.6(5)$ \\
Prior respiratory tract infection & $4.3(6)$ \\
Former kidney transplantation & $2.9(4)$ \\
Obstructive (nephro-)ureterolithiasis & $1.4(2)$ \\
Alcohol abuse & $1.4(2)$ \\
Neurogenic bladder dysfunction & $1.4(2)$ \\
Crohn's disease & $1.4(2)$ \\
Prostatic hyperplasia & $(1)$ \\
Lupus erythematodes & $(1)$ \\
AlDS & $(1)$ \\
\hline
\end{tabular}

Table 3 Radiological characteristics for AFBN

\begin{tabular}{|c|c|c|c|}
\hline \multirow{2}{*}{$\begin{array}{l}\text { General } \\
\text { characteristics }\end{array}$} & \multicolumn{3}{|c|}{ Specific features } \\
\hline & $\mathrm{CT}$ & MRI & Sonography \\
\hline \multirow{2}{*}{$\begin{array}{l}\text { Wedged- } \\
\text { shaped or } \\
\text { round }\end{array}$} & \multirow{3}{*}{$\begin{array}{l}\text { Hypodense in } \\
\text { native scan }\end{array}$} & Hypointense in T2W & \multirow{2}{*}{$\begin{array}{l}\text { Hypo-, hyper- } \\
\text { or } \\
\text { isoechogenic }\end{array}$} \\
\hline & & Isointense in T1w & \\
\hline $\begin{array}{l}\text { Uni- or } \\
\text { multifocal }\end{array}$ & & $\begin{array}{l}\text { Decreased contrast } \\
\text { enhancement in } \\
\text { T1w }\end{array}$ & $\begin{array}{l}\text { Hypoperfused } \\
\text { in Doppler }\end{array}$ \\
\hline $\begin{array}{l}\text { Non- } \\
\text { liquefactive }\end{array}$ & \multirow{2}{*}{$\begin{array}{l}\text { Decreased } \\
\text { contrast } \\
\text { enhancement }\end{array}$} & \multirow[t]{2}{*}{ Diffusion restriction } & \\
\hline $\begin{array}{l}\text { Poor } \\
\text { enhancing }\end{array}$ & & & \\
\hline No capsule & & & \\
\hline
\end{tabular}

glenohumeral septic arthritis) was associated with Staphylococcus aureus bacteremia. Some authors suggest that AFBN is a transitional stage between diffuse pyelonephritis and abscess. Indeed, a shift of AFBN to renal abscess has been described in $2.9 \%$ of our cases [11, 12, 26, 28], indicating that an abscess was the result of an insufficiently treated AFBN. Presence of microabscesses has been histologically confirmed in several AFBN specimens. In borderline stages it might be difficult to distinguish AFBN from an abscess by radiologic imaging. Yet, this discrimination is very important as AFBN does not require drainage (pus evacuation has never been reported) in contrast to an abscess. Normally AFBN exhibits diminished uptake of contrast agent, while an abscess is not perfused.

Recommendation on diagnostic, therapy and follow-up Sonography should be applied as initial screening method in all patients with upper urinary tract infection [41]. It is not sensitive enough to clarify AFBN in all cases but is helpful in detecting mass-like lesions in severe cases of AFBN, renal abscess and other renal pathologies. Doppler ultrasonography in AFBN reveals focal hypoperfusion and allows distinction from an abscess. If there is remaining dubiety and severe clinical illness, contrast enhanced CT scan can elucidate the focal pattern of kidney lesion and exclude other causes

Table 4 Treatment and interventions

\begin{tabular}{lll}
\hline Treatment/Invasive procedures & $\%(n)$ & References \\
\hline Intravenous) antibiotic therapy & 99.3 & Table 1 (all) \\
& $(137)$ & \\
Arteriography & 13.8 & {$[1,4,8-10,16,17,27$,} \\
& $(19)$ & $43,44]$ \\
Percutaneous puncture & 12.3 & {$[2,7-9,12,22,23,26-$} \\
& $(17)$ & $28,30,44]$ \\
Surgical exploration & $5.1(7)$ & {$[4,8,17,28]$} \\
Partial or radical nephrectomy & $4.4(6)$ & {$[1-4]$} \\
Ureteral stenting/stone extraction & $1.5(2)$ & {$[4,16]$} \\
following ureterolithiasis & &
\end{tabular}


of acute abdomen. Despite the underutilization of MRI in our current cohort, the technique is an alternative to CT with similar sensitivity.

Several authors reported non-response of AFBN to oral treatment in the pre-hospital setting and necessity for an escalation to intravenous antibiotics $[13,15,21,22]$ and hospitalization. As a result, intravenous administration of antibiotics should be recommended. For empiric therapy it should be taken into account that E. coli and other gram-negativ bacteria are the most frequent pathogens causing AFBN. The local infective guidelines for urinary tract infections should be considered. There is evidence that fever and disease course last longer in AFBN than in AP [37]. As a result, intravenous therapy should be continued for at least two days after defervescence and changed to oral antibiotics not before reduction of symptoms. We recommend to continue oral antibiotic intake in the post-hospital setting for at least 2 weeks and not to stop before resolution of pain. Exact time span for oral medication should be chosen depending on the course of the disease and taking into consideration that follow up examinations have shown delay of complete resolution of focal lesions for up to several weeks. Especially multifocal mass-like lesions in radiologic imaging have shown to correlate with a prolonged and complicated clinical course compared to single wedge-shaped lesions [42].

In contrast to the management of renal abscess, no drainage is primarily indicated since there is no drainable pus in AFBN. Yet, percutaneous puncture might be helpful in patients whose condition is worsening despite antibiotic therapy. In these cases cultivation of the aspirate can help to directly identify pathogen and adapt antibiotic therapy. Also, it should be taken into account that AFBN can very rarely turn into an abscess despite antibiotic therapy, especially when the pathogen is Staphylococcus aureus.

Since patients mostly respond well to conservative treatment we do not recommend a general follow-up regime that involves radiation exposure. We suggest sonography for follow up in case of proper resolution of focal lesions and uncomplicated disease course without clinical evidence for persistent renal infection. An overview of our recommendations is shown in Fig. 6.

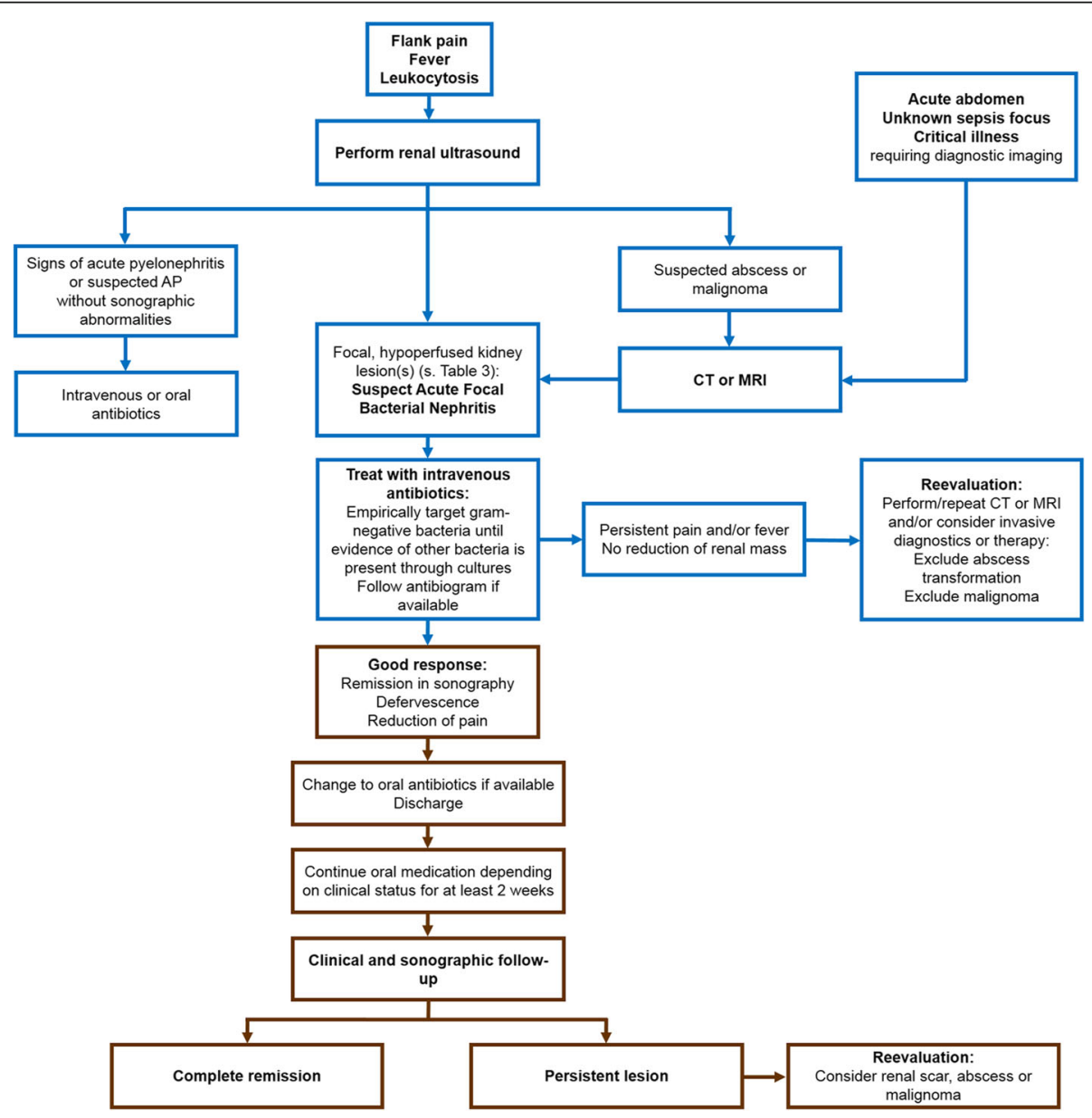

Fig. 6 Diagnostic and treatment algorithm for AFBN 


\section{Conclusions}

Correct interpretation of both clinical and radiological findings is crucial for diagnosing AFBN. Differential diagnoses include renal abscess and tumor as well as other infective diseases. A significant number of invasive procedures has been reported in the management of AFBN including percutaneous puncture, surgical exploration and even partial or radical nephrectomy. The majority of such interventions could be considered redundant, as AFBN is a kidney infection shown to be reversible upon antibiotic treatment.

\begin{abstract}
Abbreviations
AFBN: Acute focal bacterial nephritis; AIDS: Acquired immunodeficiency syndrome; AP: Acute pyelonephritis; CT: Computed tomography; E. coli: Escherichia coli; f: Female; IVU: Intravenous urography; m: Male; MRI: Magnetic resonance imaging; MRSA: Methicillin-resistant Staphylococcus aureus; PRISMA: Preferred Reporting Items for Systematic Reviews and Metaanalysis; UTI: Urinary tract infection
\end{abstract}

\section{Acknowledgements}

Not applicable.

\section{Funding}

Not applicable.

\section{Availability of data and material}

All data analysed during this study are available from the corresponding author on reasonable request.

\section{Authors' contributions}

PK performed literature research. NS and IK screened titles for eligibility. NS, IK and PK created the search strategy and conceptualized the review. NS analyzed the data and wrote the manuscript. IK and AS critically reviewed the manuscript. JN, ENL, RG and JUS gave intellectual content and/or critically reviewed the manuscript. All authors read and approved the final manuscript.

\section{Competing interests}

The authors declare that they have no competing interests.

\section{Consent for publication}

Not applicable.

\section{Ethics approval}

Not applicable.

\section{Publisher's Note}

Springer Nature remains neutral with regard to jurisdictional claims in published maps and institutional affiliations.

\section{Author details}

'Department of Urology, University Hospital Leipzig, Liebigstraße 20, 04103 Leipzig, Germany. ${ }^{2}$ Department of Urology, University Hospital of Patras, Rio 265 04, Patras, Greece. ${ }^{3}$ Department of Diagnostic and Interventional Radiology, University Hospital Leipzig, Liebigstraße 20, 04103 Leipzig, Germany.

\section{Received: 10 December 2016 Accepted: 22 March 2017}

Published online: 04 April 2017

\section{References}

1. Rosenfield AT, Glickman MG, Taylor KJ, Crade M, Hodson J. Acute focal bacterial nephritis (acute lobar nephronia). Radiology. 1979;132(3):553-61.

2. Kumar PD. Focal bacterial nephritis (lobar nephronia) presenting as a renal mass. J Investig Med. 1999;47(4):198A.

3. Li Y, Zhang Y. Diagnosis and treatment of acute focal bacterial nephritis. Chin Med J. 1996;109(2):168-72.
4. Schmidt H, Fischedick AR, Wiesmann W, Pohl J, Bramswig JHN. Acute focal bacterial nephritis. Fortschritte Auf Dem Gebiete Der Rontgenstrahlen Und Der Nuklearmedizin. 1986;145(3):245-9.

5. Moher D, Liberati A, Tetzlaff J, Altman DG, Group P. Preferred reporting items for systematic reviews and meta-analyses: The PRISMA statement. Int J Surg. 2010;8(5):336-41.

6. Harris EE, Sweat M, Katsanis WA, Aronoff GR. Case-report - Acute focal bacterial pyelonephritis (lobar nephronia) - presentation as a palpable abdominal mass. Am J Med Sci. 1992;304(5):303-5.

7. Yang CW, Kim YS, Yang KH, Chang YS, Yoon YS, Bang BK. Acute focal bacterial nephritis presented as acute renal failure and hepatic dysfunction in a renal transplant recipient. Am J Nephrol. 1994;14(1):72-5.

8. Nosher JL, Tamminen JL, Amorosa JK, Kallich M. Acute focal bacterial nephritis. Am J Kidney Dis. 1988;11(1):36-42.

9. Zaontz MR, Pahira JJ, Wolfman M, Gargurevich AJ, Zeman RK. Acute focal bacterial nephritis - a systematic approach to diagnosis and treatment. J Urol. 1985:133(5):752-7.

10. Rigsby CM, Rosenfield AT, Glickman M, Hodson J. Acute hemorrhagic focal bacterial nephritis - findings on B-scan ultrasonography and computed tomography. Am J Roentgenol. 1986;147(5):1087.

11. Wood GNI, Kalra PA, Mamtora H, Waldek S, Donoghue DJO. A febrile patient with a renal space-occupying lesion evolving into renal abscess - acute focal bacterial nephritis. Nephrol Dial Transplant. 1995;10(7):1248-50.

12. Adams N, Johnson MD, Storm DW, Maves RC. Acute focal bacterial nephritis due to methicillin-resistant Staphylococcus aureus in an immunocompetent adult. Infection. 2014:42(2):433-6.

13. Iga R, Uchino H, Kanazawa K, Usui S, Miyagi M, Kumashiro N, Hirose T. Acute focal bacterial nephritis in an occupational allergy. Lancet Infect Dis. 2014; 14(7):656

14. Cho DK, Shon SH, Kim YL, Cho WH, Park DC, Lee JK. Clinical aspects of acute focal bacterial nephritis (AFBN). J Am Soc Nephrol. 1994;5(3):389.

15. Cuenca R, Simeon CP, Torrents C, Fonollosa V. Acute focal bacterial nephritis - a case-report. Med Clin. 1990;95(6):234.

16. Funston MR, Fisher KS, Vanblerk PJP, Bortz JH. Acute focal bacterial nephritis or renal abscess - a sonographic diagnosis. Br J Urol. 1982;54(5):461-6.

17. McDonough WD, Sandler CM, Benson GS. Acute focal bacterial nephritis - focal pyelonephritis that may simulate renal abscess. J Urol. 1981;126(5):670-3.

18. Montejo M, Santiago MJ, Aguirrebengoa K, Garcia B, Goicoetxea J, Martin A. Acute focal bacterial nephritis: report of four cases. Nephron. 2002;92(1):213-5.

19. Cox SM, Cunningham FG. Acute focal pyelonephritis (lobar nephronia) complicating pregnancy. Obstet Gynecol. 1988;71(3):510-1.

20. Boam WD, Miser WF. Acute focal bacterial pyelonephritis. Am Fam Physician. 1995;52(3):919-24

21. Dourthe O. Acute focal bacterial nephritis - a new uroradiological entity. Gazette Medicale. 1991;98(35):8

22. Joss N, Baxter G, Young B, Buist L, Rodger RS. Lobar nephronia in a transplanted kidney. Clin Nephrol. 2005;64(4):311-4.

23. Levy DA, Seftel A, Schulak JA. Acute focal bacterial nephritis in a kidneytransplant. Clin Transpl. 1992;6(4):325-7.

24. Thomalla JV, Gleason P, Leapman SB, Filo RS. Acute lobar nephronia of rena transplant allograft. Urology. 1993;41(3):283-6.

25. Angulo JC, Loizaga A, de Garay MG, Flores N. Acute focal bacterial nephritis in a case of AIDS. Actas Urol Espanolas. 1993;17(1):84-5.

26. McCoy Rl, Kurtz AB, Rifkin MD, Kodroff MB, Bidula MM. Ultrasound detection of focal bacterial nephritis (lobar nephronia) and its evolution into a renal abscess. Urol Radiol. 1985:7(2):109-11.

27. Sawamura T, Nakada T, Sasagawa I, Yamaguchi T, Suzuki Y, lijima Y. Imaging studies on acute focal bacterial nephritis. Int Urol Nephrol. 1993;25(3):221-8.

28. Lee JK, McClennan BL, Melson GL, Stanley RJ. Acute focal bacterial nephritis: emphasis on gray scale sonography and computed tomography. AJR Am J Roentgenol. 1980:135(1):87-92.

29. Maeshiro T, Hokama A, Fujita J. Acute focal bacterial nephritis. BMJ Case Reports. 2014:2014:bcr2014205199. doi:10.1136/bcr-2014-205199.

30. Falcon MV, Finn BC, Korin L, Emery NC, Young P. Acute focal bacterial nephritis by methicillin-resistant Staphylococcus aureus. Medicina. 2013;73(3):288-90.

31. Custovic Z, Sosa S. Focal bacterial nephritis masquerading as renal cell carcinoma: case report. Acta Clin Croat. 2011:50(1):113-4.

32. Rosi P, Petroni PA, Valli PP, Marzi M, Morcellini R, Barzi F. Lobar nephritis: echographic diagnosis and follow-up. Arch Ital Urol Androl. 1996;68(5 Suppl):79-82 
33. Choyke PL, Kressel HY, Pollack HM, Arger PM, Axel L, Mamourian AC. Focal renal masses: magnetic resonance imaging. Radiology. 1984;152(2):471-7.

34. Hoddick W, Jeffrey RB, Goldberg HI, Federle MP, Laing FC. CT and sonography of severe renal and perirenal infections. AJR Am J Roentgenol. 1983;140(3):517-20.

35. Rathaus V, Werner M. Acute focal nephritis: its true sonographic face. Isr Med Assoc J. 2007;9(10):729-31.

36. Esteban JM, Gomes E, Santamaria JF, Maldonado L. Hyperechoic focal bacterial nephritis: findings on contrast-enhanced Colour Doppler ultrasound. Eur J Ultrasound. 2001;13(3):201-4.

37. Ha SK, Kim KW, Suh JK, Park CH, Park SH. Acute focal bacterial nephritis (AFBN) as a frequent subset of acute pyelonephritis (APN) with relatively good response to early antibiotics. J Am Soc Nephrol. 1996;7(9):A0640,

38. Pelage J, Helenon O, Szwagier C, Cornud F, Melki P, Belin X, Moreau JF. Pseudotumoral appearance of focal acute pyelonephritis. J Radiol. 1996; 77(4):271-4.

39. Ameur A, Lezrek M, Boumdin H, Beddouch A. Focal bacterial nephritis: diagnosis and treatment. Prog Urol. 2002;12(3):479-81.

40. Ruiz Dominguez JL, Chicharro Molero JA, Marchal Escalona C, Fuentes Lupianez C, Burgos Rodriguez R. Acute focal bacterial nephritis. Pathology mimicking renal masses. Actas Urol Esp. 1994;18(4):308-11.

41. Bonkat G, Pickard R, Bartoletti R, Bruyère F, Geerlings SE, Wagenlehner F, Wullt B, et al. EAU Guidelines on Urological Infections. Eur Assoc Urol. 2017: 15-16. https://uroweb.org/guideline/urological-infections/.

42. Huang JJ, Sung JM, Chen KW, Ruaan MK, Shu GH, Chuang YC. Acute bacterial nephritis: a clinicoradiologic correlation based on computed tomography. Am J Med. 1992;93(3):289-98.

43. Dochy P, Lemmens L, Berneman Z, Van Herreweghe W. Acute focal bacterial nephritis (acute lobar nephronia). J Belg Radiol. 1986;69(6):431-4.

44. Harpole Jr JH, Gammill SL. Radiology case of the month. Focal nephritis. J Tenn Med Assoc. 1988;81(10):636.

\section{Submit your next manuscript to BioMed Central and we will help you at every step:}

- We accept pre-submission inquiries

- Our selector tool helps you to find the most relevant journal

- We provide round the clock customer support

- Convenient online submission

- Thorough peer review

- Inclusion in PubMed and all major indexing services

- Maximum visibility for your research

Submit your manuscript at www.biomedcentral.com/submit

) Biomed Central 